\title{
Syrians, palestinians and iraqi refugees in lebanon
}

\section{Introduction}

In February 2011, the 'Arab Spring' begun in Syria.

The conflict between protestors and government forces in Syria has developed into a complex crisis involving many parties, and led to a unique humanitarian disaster.

As the years are passing, the situation of the civilians in Syria along with the Syrian refugees is getting worse.

Lebanon, despite its small size, is hosting over 1.3 million refugees from Syria, equal to more than $20 \%$ of Lebanon's original population. ${ }^{1}$

Not less than 20 million people in Syria are in need of humanitarian help; in addition 4.1 million coasted over the border as refugees in neighbouring countries. These are becoming a big burden on the welcoming countries. Almost 1.3 million registered Syrians evacuated their country and established in Lebanon, where in conjunction with Palestinian refugees they now make up more than a quarter of the population.

\section{Figures and facts of syrian refugees}

Refugees fleeing Syria continue to enter Lebanon on a daily basis.

Lebanon has experienced a massive influx of refugees the past 5 years including 1.3 million people escaping from conflict in Syria.

This represents almost 1 in every 5 people in Lebanon.

This increased population has a dramatic impact on country's social, economic aspects along with the local infrastructure that is deteriorating rapidly. Half of these refugees are children with an uncertain future, growing in a climate of lack of trust and a lot of fear. Tension between different ethnic groups is rising and they are often subjects to violence and discrimination.

According to Fox news, report (10/09/2016), 30000 Syrians child born in Lebanon as refugees is at risk of statelessness while UNHCR gives a number of 50000 .

Overview of the syrian refugee crisis in lebanon syrian refugees influx

With beginning of the Syrian crisis in March 2011, Syrian citizens were displaced and the number of Syrian refugees in Lebanon started to rise. According to estimates of the United Nation High Commissioner for Refugees (UNHCR), there are 927,638 Syrian refugees in Lebanon of whom 879,907 are registered and around 47,731 are awaiting registration. The Lebanese government estimate for Syrian refugees is more than one million. With the growing influx of refugees, local communities are under rising pressure in terms of livelihood resources, such as food, education, health services, and employment. The impact of these refugees challenges the already precarious stability of the country in general and host communities in particular.

Volume 8 Issue I - 2018

\author{
Robert Sacy, Yolla Nassif, Dany Hamod, Pia \\ Kiwan \\ Neonatal Intensive Care Unit, Department of Pediatrics, Saint \\ George Hospital University Medical Center, Lebanon
}

Correspondence: Robert Sacy, Neonatal Intensive Care Unit, Department of Pediatrics, Saint George Hospital University Medical Center, Beirut, Lebanon. P.O. Box: 166 378, Achrafieh, Beirut II 00 2807, Lebanon, Tel 96|320|455, Email rnsacy@info.com.lb

Received: December 14, 2017 | Published: January 31, 2018

\section{Number of refugees increasing by months and years (figure I)}

\section{Ratio male female and age}

More than half of the Syrian refugees in Lebanon are below 18 years of age. The predominance of children and adolescents among the Syrian refugee population is likely due to the fact that many men remained in Syria either to protect their businesses and houses or, in some instances, join the fighting forces. The lack of adult males exacerbates the vulnerability of Syrian women and children, who are facing an insecure environment subject to risks of sexual violence, child marriage, child labor, and illicit activities (Table 1).

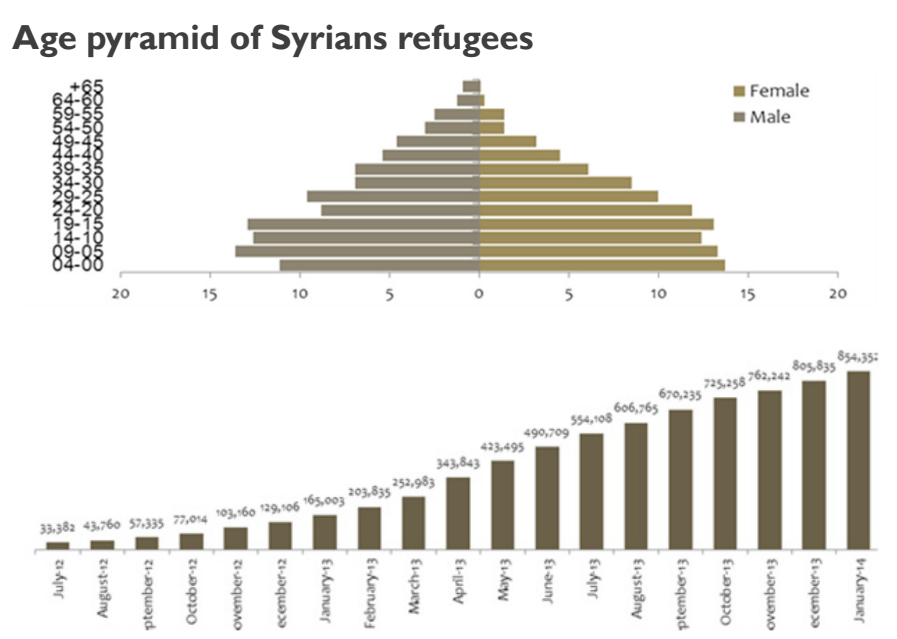

Figure I Number of registered Syrian refugees between July 2012 and January 2014.

Source: UNHCR [2] Syria Regional Refugee Response. 
Table I Registered Syrian refugees by sex and age (\%)

\begin{tabular}{lll}
\hline Age & Females & Males \\
\hline $0-4$ & 9 & 10 \\
$5-11$ & 10 & 11 \\
$12-17$ & 6 & 6 \\
$18-59$ & 25 & 20 \\
60 and above & 2 & 1 \\
Total & 52 & 48 \\
\hline
\end{tabular}

Source: UNHCR.

\section{Registration}

Despite the efforts of these NGOs, around 30,000 Syrians born as refugees in Lebanon are not registered with any government leaving them in statelessness and depriving them from their basic rights such as going to school, having a job or even getting married. The United Nations refugee agency estimated that around $70 \%$ of infants born in Lebanon to Syrian refugees are off the books mostly due to the unavailability of their parents' marriage license. Therefore, acquiring legal documentation by the Lebanese authorities for Syrian newborns refugees is a major concern.

For instance, a young mother claimed that the barriers to registering resided in the paperwork required by Lebanese authorities. "It took us eight months to register Mohammed," she said. "I want to register my youngest but the problem is they asked for documents from Syria, but we can't go back. (Human Rights watch report).

The U.N. refugee agency and the NGOs have been raising awareness among Syrian refugees across the Middle East to register their children; especially in Lebanon were the highest number of nonregistered newborn is detected, in contrast to Jordan were $70 \%$ of children born to Syrian refugees are registered due to facilities in the process and lesser phases then those in Lebanon.

"If you think in terms of the hope for these children to go back to Syria one day, if and when conditions allow, not having any legal document will make them like ghosts going back to their country," UNICEF's senior child protection officer Isabella Castrogiovanni said.

\section{Impact of the syrian refugees on host communities and poverty}

The huge influx of Syrian refugees to the country, classified Lebanon as the biggest host country for Syrian refugees in the region. The number of refugees is projected to increase further, pressure on Lebanon in general and on the already poor hosting communities in particular increased poverty and vulnerability according to M.S.F. USA 2016 report.

Poverty incidence has risen to 53 per cent in the North, 42 per cent in the South and 30 per cent in Beqaa, compared with the national poverty rate of 28 per cent.

The total Poverty is accentuated even more in the rural regions of the North, hitting more than 60 percent of the population of those two regions.

\section{Housing}

Escaping the violence from Syria has pushed the families to live in very difficult conditions. The majority of these refugees fled Syria with no possessions and now lives in often cramped conditions. These families are deprived from food, clothing, mattresses, cooking equipment, basic shelter and even hygiene items.
At the beginning, many refugees settled with families or friends in various host communities. As crisis prolonged, displaced Syrians resorted to rented accommodation. However, with limited job opportunities and low wages, they have experienced limited capacity to afford rent.

$59 \%$ of families have one room as a shelter and $22 \%$ of large families ( $8+$ members) are living in a single room. $82 \%$ are dependent on food aid and $73 \%$ do not have enough food for the whole family.

Implementing a number of emergency programs across Lebanon was a need to provide urgent assistance: NGOs and global organizations are providing money, medication, clothing, food vouchers, food packages, hygiene kits and drawing books for children, along with basic shelter repairs.

By the end of 2012, more than 6,000 households benefited from housing assistance from international organizations and local charities, including access to collective centers, the rehabilitation of empty houses or cash assistance. Refugees have also resorted to illegal occupation of houses and land, which are sometimes unsuitable for housing. So they reside with relatives, or they rent apartments. As more refugees arrive, living conditions are shifting, and those who have already settled are depleting their savings. Unable to cover the high rents, these refugees are erecting tented settlements.

For example, in May 2014, one round of 800 food packages and a one-off round of 700 hygiene kits and 700 children's kits were successfully spread to families in the Beqaa Valley region.

The rise of infectious diseases and scabies indicate the bad living conditions that Syrian refugee population have been forced to endure.

Note that the central Government prohibited any intervention for the enhancement of tent settlements in the country under a policy not to create camps for Syrian refugees. As a result, the demand for shelter has exceeded supply in many parts of the country with more than 60 per cent of Syrian refugees living in rented accommodation.

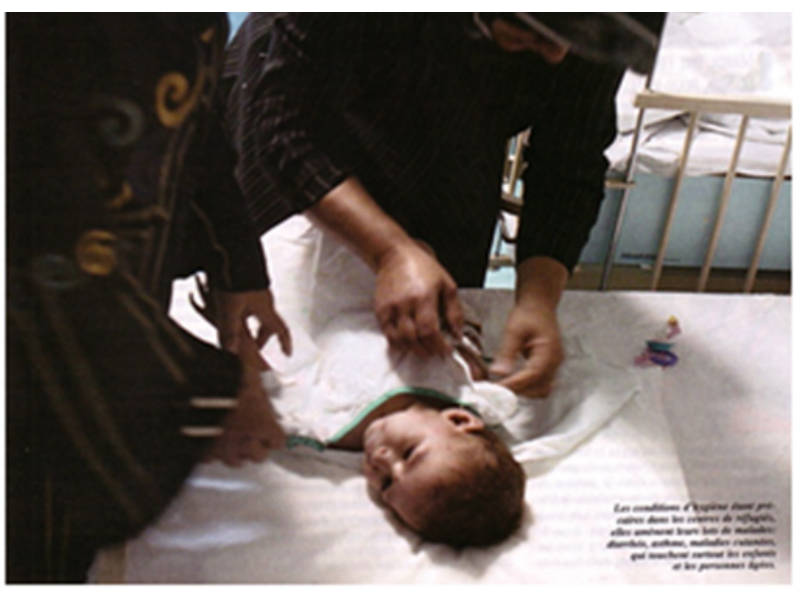

\section{Water and sanitation}

Water and sanitation remains a challenging matter for Syrian refugees given the deficient living conditions they are enduring. As a result, many are highly prone to water-related diseases, such as diarrhea, skin disease and Hepatitis.

With the high influx of Syrian refugees since 2011, water, sanitation and hygiene conditions are failing. An assessment of these conditions in the Bekaa and the North showed high levels of contamination of drinking water, inadequate sanitation facilities, as well as poor hygiene. 


\section{Health care}

Many international and local Non-Governmental Organizations have been working on providing financial, medical and humanitarian support for the Syrian refugees.

Syrian refugees have access to primary healthcare services that are provided for free by public dispensaries of the Ministry of Social Affairs and the Ministry of Public Heath (MoPH), in addition to services provided by humanitarian international organizations and local NGOs. However, these services seem insufficient and are unable to accommodate the additional significant increase of demand especially in terms of reproductive health.

Syrian refugee children in Lebanon can also obtain vaccination against several diseases, such as measles and polio, provided at national primary health care facilities and through vaccination campaigns organized by the MoPH with other partners like UNICEF and UNHCR mobile medical units are also made available in most host communities.

These services are limited to registered refugees, rendering unregistered refugees with very limited healthcare support. Even though other healthcare costs, such as hospitalization, are subsidized by international agencies (mainly UNHCR), a large number of refugees are still unable to afford the remaining costs.

\section{Cost of hospitalization}

If refugees are registered at UNHCR, they are allowed to be hospitalized in certain circumstances mainly in NICU and PICU for a short stay with a top cost that cannot be over headed.

Sometimes after one weak or less, UNHCR refuses to pay the rest of the amount and they are obliged to leave the hospital without a clear diagnosis or a good treatment.

UNHCR pays $90 \%$ of the bill at a reduced prices and the rest $10 \%$ should be paid by the refugees. Private hospitals have a tendency to refuse hospitalization due to delayed and low bills payment.

\section{Increase of admissions of refugees}

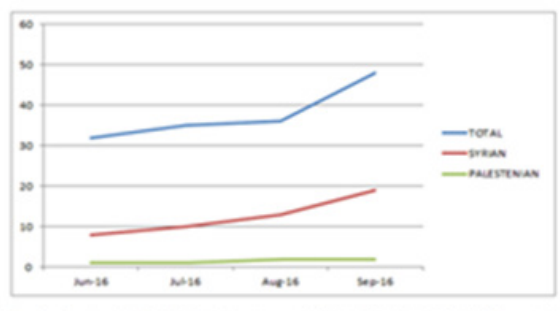

There is an increase in the number of refugees across lebanon due to the facilities provided education

The Ministry of Education and Higher Education (MEHE) facilitated access to education for Syrian refugees to all public schools.

However, both students and schools continue to face challenges Classrooms in the public Government schools in Lebanon are generally not overcrowded. However, the high concentration of Syrian refugees in host communities has led to the overcrowding of schools that were previously under-populated.
Syrian refugee students face several obstacles that not only hinder their access to education (transportation costs and discrimination), but also affect their ability to learn in school, such as differences between the curricula and language (French or English are the languages of instruction for most school subjects), while Arabic is the only language in Syria.

According to the NGO Save the Children if 3, 5 million children of refugees in the world will not go to school in 2016, in 2017500000 children Lebanese and refugees will not go to school.

\section{Education profile of syrian refugees}

The educational attainment of Syrian refugees is generally low with one out of three either illiterate or can read and write. Three quarters have primary education or below and only three per cent have obtained university education. Males and females seem to have similar educational levels, although slightly less females than males completed secondary or university education.

\section{Distribution by sex and education level}

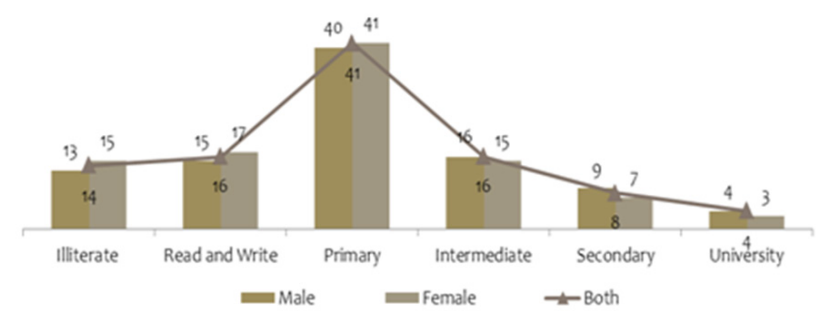

Source: UNHCR ${ }^{1}$

\section{Reasons to avoid education}

\begin{tabular}{ll}
\hline Reasons for not Being Enrolled (\%) & Percentage (\%) \\
\hline Cannot afford school fees & 47 \\
No places in schools or no schools nearby & 27 \\
Too late for school registration & 25 \\
Difficulty following the curriculum and the foreign language I 9 \\
Do not want to attend school & 12 \\
Consider school not safe or to avoid conflicts & 9 \\
Not registered with the UNHCR & 8 \\
Child working & 7 \\
\hline
\end{tabular}

Other reasons of not attending school include convictions that school is not of value, work is more rewarding or girls must not attend schools to take care of younger siblings.

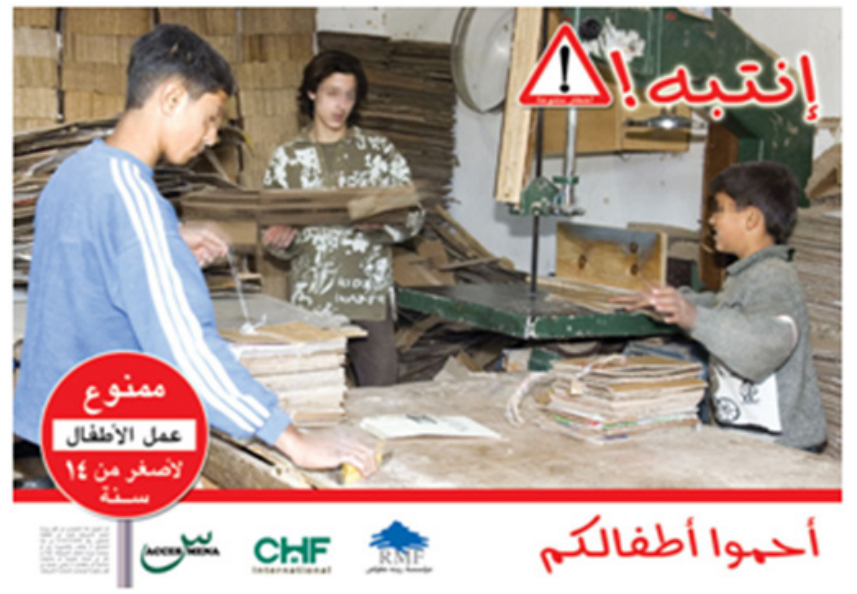




\section{Education situation in 20 I 6}

\section{Few numbers}

Ministry of education launched school campaign: Back to school.

94 million USD were paid through UNHCR, UNICEF and World Bank together with other donators. 1278 public schools received them. 115 schools provide a second shift in the afternoon.

200000 Syrians children refugees in Lebanon between 3 and 14years in 2016 had access to certified education in Lebanon. This number is out of a total of 417000 registered child refugees in Lebanon leaving 217000 out of school.

Economic activity rate for syrian refugees, palestinian refugees and lebanese population aged I 5 and above

\begin{tabular}{llll}
\hline Percentage & $\begin{array}{l}\text { Syriens } \\
\mathbf{- 2 0 1 3}\end{array}$ & $\begin{array}{l}\text { Palestinians } \\
\mathbf{- 2 0 1} \text { I }\end{array}$ & $\begin{array}{l}\text { Lebanese } \\
\mathbf{- 2 0 0 7}\end{array}$ \\
\hline Male & 70 & 71 & 67 \\
Female & 19 & 15 & 21 \\
Total & 47 & 42 & 43
\end{tabular}

\section{Wages and benefits}

Working Syrian refugees have an average monthly income of LBP 418,000 (280usd); the average income of females (LBP 248,000-160 USD) is 43 per cent less than males (LBP 432,000).

The average income of Syrian refugees is significantly lower than the minimum wage in Lebanon of 675,000 LBP (450usd) and less than the 2007 poverty line of USD 4.00 (LBP 6,000) per person per day.

However, there are a lot of jobs that are being attributed to Syrian refuges instead of the Lebanese population. Work puts the Syrians at risk of health problems.

Ministry of Social Affairs together with War Child and Dar al Amal have conducted researches on violence against children, sexual abuse and child work.

Percentage of syrian workers who are exposed (either always or sometimes) to work-related hazards

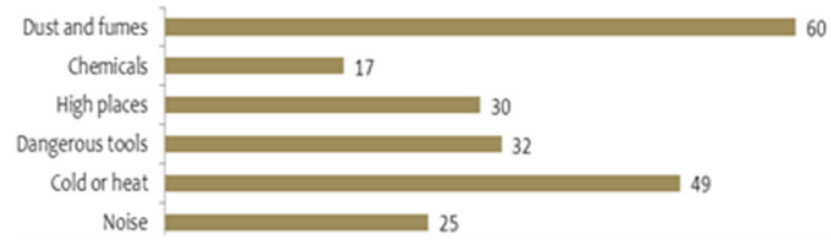

Percentage of syrian workers who suffer from one or more work-related health problems

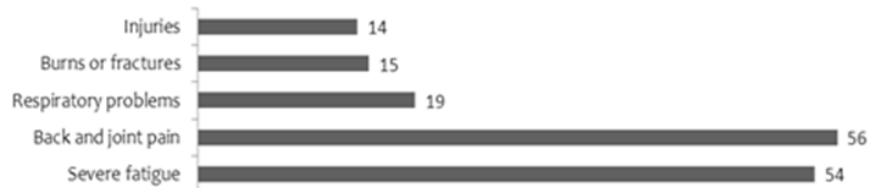

Percentage of syrian workers who suffer from work-related issues

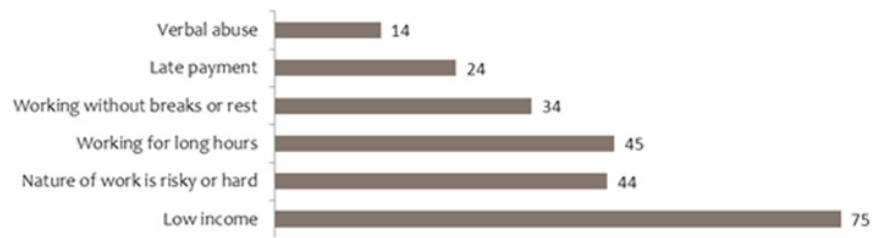

\section{Competition on jobs and businesses}

Prior to the Syrian crisis, labor market in Lebanon was characterized by low activity rates, especially among women, relatively high unemployment rates (eight per cent in 2004), and a growing informal sector. The employment situation has, unsurprisingly, worsened with the huge increase in labor supply and the large number of Syrian entrants along with the pre-existing great number of Lebanese jobseekers looking for employment, leading to an increase in the unemployment rate and making access to jobs even harder.

\section{Competition for jobs and decreased income}

Syrian workers are unskilled workers with low educational attainment and high willingness to work under difficult working conditions. This threatens the Lebanese workers, mainly in the construction, agriculture and, to a lesser extent, the services sector. Competition between Lebanese and Syrian workers is quite high, given that Syrian workers work for lower salaries, longer hours and without social security benefits.

The sudden increase in the labor supply and the availability of cheap Syrian labor explains the decline in wages and the strain on jobs, which is translated into more limited job opportunities for Lebanese national. According to FAO, the increase in the number of Syrian workers caused a reduction of 60 per cent in daily wages.

\section{Syrian work force in lebanon}

It is estimated that two years after the outbreak of the conflict in Syria, Syrian workforce in Lebanon increased between 30 and 50\%, comprising about $14 \%$ of Lebanon's total workforce (Civil Society knowledge Center $^{3}$ ).

\section{Children killed in syria}

More than 10,000 children have been killed in the Syrian civil war, the United Nations says, while many more are subjected to "unspeakable" suffering, including rape, torture and recruitment for combat.

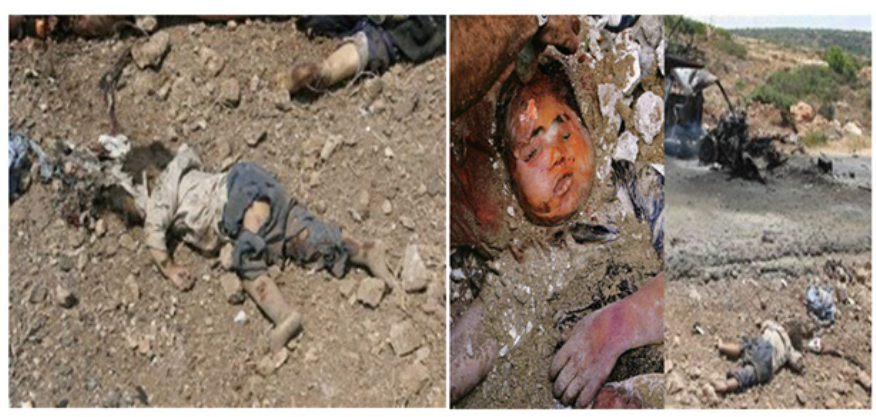

Thousands more have also been forced to flee their homes during the years of conflict, according to a report released to the Security Council and posted on the UN website. 


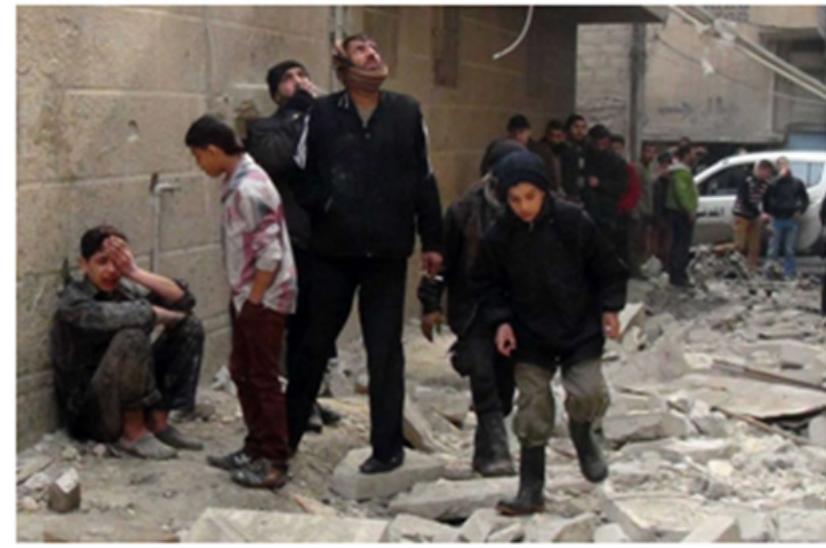

Syrian people inspect building damage following an airstrike

A young Syrian boy cries as others inspect the damage following a reported government airstrike in Aleppo. (AFP: Mahmud Al-Halabi).

Almost every day, 5 to 10 children are killed in Syria by airplane bombings, mainly in Aleppo in recent fights.

45 persons were killed on October 172016 in 24 hours in Aleppo, among them 75 children (L'Orient-Le Jour).

Quarter of civilians Quarter of civilians killed are women and children British Medical Journal report says bombing and shelling most likely to cause child deaths.

Women and children make up nearly a quarter of nearly 80,000 civilians killed during the $4 \frac{1}{2}$-year-old Syrian war, the vast majority being in areas controlled by anti-government forces. The main causes of civilian fatalities have been bombing, shelling, shooting, poison gas, and executions.

According to a report published in the British Medical Journal, the use of "explosive weapons in populated areas in Syria has disproportionately lethal effects on women and children and should be urgently prohibited".

\section{Casualties of the syrian civil war}

By mid-September 2016, the opposition activist group Syrian Observatory for Human Rights (SOHR) reported the number of children killed in the conflict had risen to 15,099 , while at the same time 10,018 women were also killed.

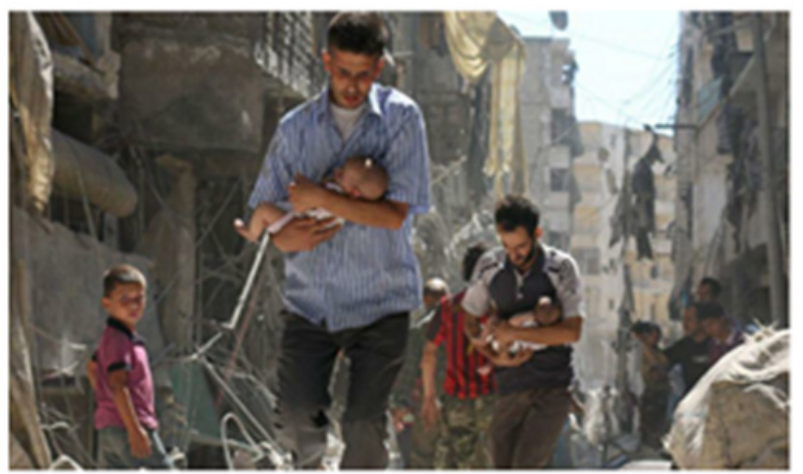

Since the beginning of 2012 hundreds of young people have been killed each month in the Syrian civil war. Seven hundred children died in January 2013 alone, according to a report by the Oxford Research
Group published in November. The report also said that 11,240 people aged 17 and younger were killed between March 2011 and August 2013.

\section{A petition by i.p.a. was done to protect} children from war

\begin{tabular}{|c|}
\hline 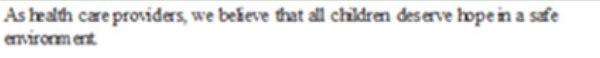 \\
\hline The petition a sks gor remments to: \\
\hline $\begin{array}{l}\text { a). The UN convertion on the Rights of the Chld, which all courtries of the } \\
\text { world have signed, must be fully implemented everyuhere, especially in } \\
\text { corflict zones. }\end{array}$ \\
\hline 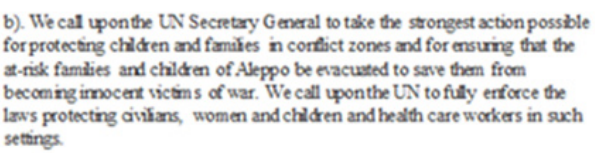 \\
\hline 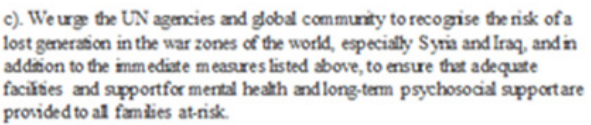 \\
\hline
\end{tabular}

\section{Children soldier}

\section{By michelle nichols, reuters}

United Nations: Syrian troops and rebels are recruiting children to fight in the country's civil war and some have been tortured by government forces for having links to the opposition, U.N. chief Ban Ki-moon said in a report.

\section{Children armed to fight}
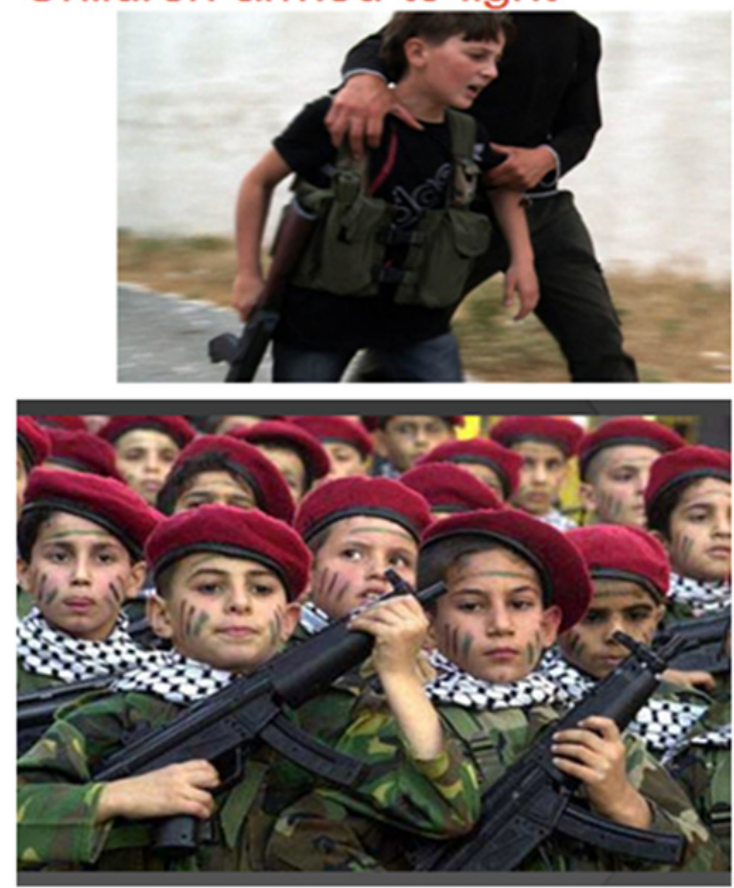

\section{Palestinians refugees}

After Yarmouk camp battle near Damascus, 42000 Palestinians refugees from Damascus arrived to Lebanon adding to the 450000 Palestinians already refugees in Lebanon. 16000 arrived in one week.

UNRWA is having financial difficulties, because donator's nations are no more interested to help Palestinians for so many years. UNRWA offices in Palestinians camps are closing thus not being able to help in the hospitalization of children. 
Children are dying because they are denied of admission to hospitals, mainly in NICU and PICU and if they are admitted and cannot pay the required $10 \%$ not covered by UNHCR, for investigations, the parents answer is often: "let him dye", "we cannot pay", "we will bring another one in good health".

\section{War in iraq}

According to the Iraqi Red Cross, more than 33\% of handicapped children are victims of war and bad treatments. UNICEF in Iraq said that it needs 42 million dollars only to give water and food for Iraqi children. Only $30 \%$ of children in Iraq have access to drinking water. Cases of Cholera have been declared. Iraqi Children refugees: Most of them are Christian refugees running away from ISIS. They come to Lebanon for a limited period hoping to get an immigration visa to western countries.

They live in churches, have no medical coverage and some N.G.O. are trying to raise money, food and sometimes to hospitalize them if urgently needed. As opposing to Syrian and Palestinian refugees, no International organization is taking care of Iraqi refugees in Lebanon.

\section{What is birth and beyond assameh?}

With a group of volunteers, civilians and pediatricians, an N.G.O. named Birth and Beyond/Assameh was created.

Purpose is to create a pediatric department with all the facilities and a very well equipment that may receive sick patients from poor economic conditions whether Lebanese, Syrians, Palestinians or undetermined nationality that are usually Syrians born in Lebanon but whom Syrian regime denies the right of nationality for several reasons.

Knowing that in Lebanon, the rate of birth is around 60000 newborns per year, we have 750000 newborns in Lebanon which are Syrians refugees and most of them are not registered to Syrian authorities and have an undetermined nationality.

Carlos slim pediatric center: It is the pediatric department at Quarantina Governmental Hospital equipped by birth and beyond assameh.

\section{Equipment includes:}

-A Neonatal Intermediate Care Unit of 16 incubators.

-A Pediatric Intensive Care Unit of 4 beds.

-A pediatric department of 12 beds.

-An Out Patient Department with vaccination program.

\section{Before}

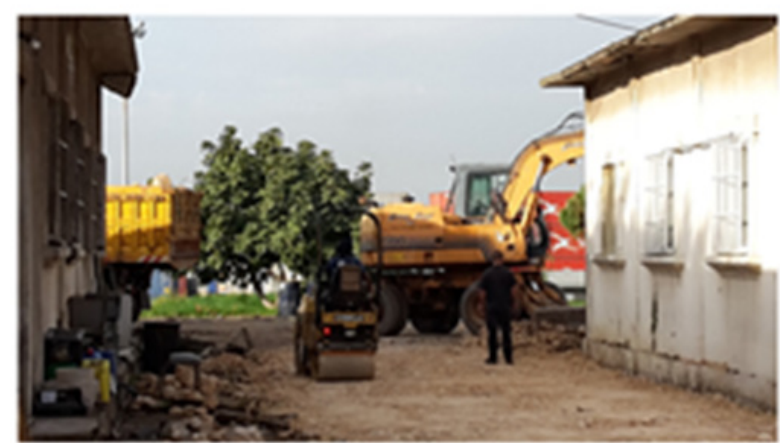

However after so many efforts,

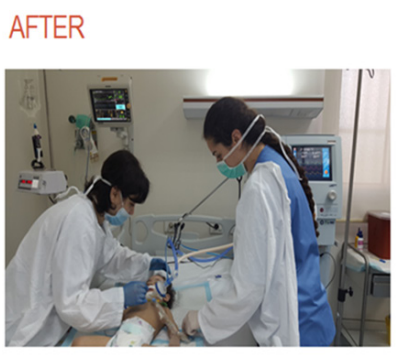

AFTER

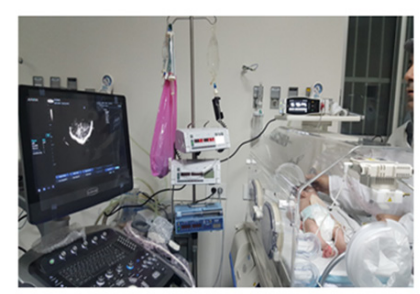

New ambulance Mobile Intensive care unit

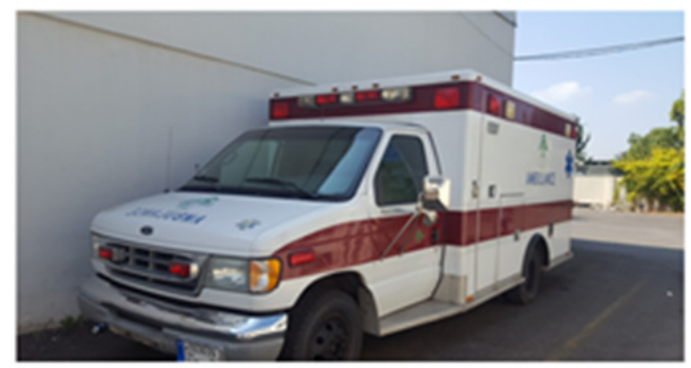

\section{Equipment available}

- Pediatric and neonatal Mechanical Ventilation, Bubble Continuous Positive Airway Pressure, High Frequency Oscillation and Nitric Oxide.

- Monitoring, Electrocardiography, Video EEG, Echography, Portable X-ray machine with CR technology.

- Abbott point of care, a diagnostic machine which gives results with 3 drops of blood within minutes.

- One operating room equipped for neonatal interventions.

In addition to the classical equipment's existing in the old hospital.

\section{Missing material}

i. CT scan

ii. MRI.

iii. Performing laboratory workup at any time of the day.

iv. Material for gastroscopy, bronchoscopy and colonoscopy.

v. Surgical material for neonatal laparoscopic surgery.

\section{Conclusion}

Syrian refugees are uncontrollable, now a day presenting a huge impact on the medical sector in Lebanon. They are in need of humanitarian help, which is at the same time considered a health disaster since the majority are not being able to be hospitalized except at the governmental hospitals. Birth and Beyond/Assameh created a pediatric department in order to receive sick patients from poor economic conditions whether Lebanese, Syrians, Palestinians. ASSAMEH now a day being able to solve around $80 \%$ of the medical conditions, in the hope to grow up more their materials so they will be able to cover all medical conditions.

\section{Acknowledgements}

None.

\section{Conflicts of interest}

None. 


\section{References}

1. http://www.unher.org/statistics/country/556725e69/unher-globaltrends-2014.html
2. http://www.unhcr.org/statistics/country/5399a14f9/unher-globaltrends-2013.html

3. http://civilsociety-centre.org/gen 